\title{
CXCR4 and CXCR7 Signaling Pathways: A Focus on the Cross-Talk Between Cancer Cells and Tumor Microenvironment
}

\author{
Sara Santagata ${ }^{\dagger}$, Caterina leranò ${ }^{\dagger}$, Anna Maria Trotta, Anna Capiluongo, \\ Federica Auletta, Giuseppe Guardascione and Stefania Scala* \\ Research Department, Microenvironment Molecular Targets, Istituto Nazionale Tumori-IRCCS-Fondazione "G. Pascale", \\ Napoli, Italy
}

OPEN ACCESS

Edited by:

Gennaro llardi,

Federico II University Hospital, Italy

Reviewed by:

Zhichao Xi,

Shanghai University of Traditional

Chinese Medicine, China

Daniela Omodei,

Institute of Biostructure and

Bioimaging (CNR), Italy

*Correspondence:

Stefania Scala

s.scala@istitutotumori.na.it;

scalaste@gmail.com

${ }^{\dagger}$ These authors have contributed equally to this work

Specialty section:

This article was submitted to Molecular and Cellular Oncology, a section of the journal

Frontiers in Oncology

Received: 04 August 2020 Accepted: 25 March 2021

Published: 15 April 2021

Citation:

Santagata S, leranò C, Trotta AM,

Capiluongo A, Auletta F,

Guardascione G and Scala S (2021)

CXCR4 and CXCR7 Signaling

Pathways: A Focus on the Cross-Talk

Between Cancer Cells and Tumor

Microenvironment.

Front. Oncol. 11:591386.

doi: 10.3389/fonc.2021.591386
The chemokine receptor 4 (CXCR4) and 7 (CXCR7) are G-protein-coupled receptors (GPCRs) activated through their shared ligand CXCL12 in multiple human cancers. They play a key role in the tumor/tumor microenvironment (TME) promoting tumor progression, targeting cell proliferation and migration, while orchestrating the recruitment of immune and stromal cells within the TME. CXCL12 excludes T cells from TME through a concentration gradient that inhibits immunoactive cells access and promotes tumor vascularization. Thus, dual CXCR4/CXCR7 inhibition will target different cancer components. CXCR4/CXCR7 antagonism should prevent the development of metastases by interfering with tumor cell growth, migration and chemotaxis and favoring the frequency of T cells in TME. Herein, we discuss the current understanding on the role of CXCL12/CXCR4/CXCR7 cross-talk in tumor progression and immune cells recruitment providing support for a combined CXCR4/CXCR7 targeting therapy. In addition, we consider emerging approaches that coordinately target both immune checkpoints and CXCL12/CXCR4/CXCR7 axis.

Keywords: CXCR4, CXCR7, tumor microenvironment, immune cells, cancer

\section{INTRODUCTION}

Chemokines are small chemoattractant molecules that control cell migration, proliferation and survival in physiological and pathological processes including cancer (1). They are divided into CC, CXC, XC and CX3C subfamilies based on their cysteine motif (2) and are functionally categorized as inflammatory (CXCL1, CXCL2, CXCL3, CXCL5, CXCL7, CXCL8, CXCL9, CXCL10, CXCL11, and CXCL14) and homeostatic chemokines (CCL14, CCL19, CCL20, CCL21, CCL25, CCL27, CXCL12 and CXCL13) (3). Chemokines act on chemokine receptors, G-protein coupled-7 transmembrane receptors (GPCRs) grouped according to chemokines nomenclature (CCR, CXCR, XCR and CX3CR) (2). About 50 chemokines and 23 human chemokine receptors have been identified (4) including the atypical chemokine receptors (ACKRs), unable to trigger the canonical G protein-signaling and thus called decoys, scavengers or interceptors. Four molecules are included in the ACKR subfamily: ACKR1, or duffy antigen receptor for chemokines (DARC); ACKR2, or D6 or CCBP2; ACKR3, also 
called CXC-chemokine receptor 7 (CXCR7) or RDC1; and ACKR4, or CC chemokine receptor-like 1 (CCRL1) (5). In TME, both immune cells and stromal cells, express chemokines that regulate tumor vascularization and invasion (6). Herein, the focus is on the CXCL12 that activates CXCR4 and CXCR7. CXCL12, initially known as stromal-derived factor 1 (SDF-1), encoded on chromosome 10q11, is a homeostatic chemokine secreted in lymph nodes, kidney, brain, colon, lung and liver by stromal cells, fibroblasts and epithelial cells in six different isoforms. CXCL12 regulates adhesion of tumor cells with laminin, fibrinogen, stromal cells and endothelial cells (ECs) by activating cell surface adhesion molecules $(7,8)$. CXCR4 is a coreceptor for Human Immunodeficiency Virus (HIV)-1 entry (9) and binds solely CXCL12, while CXCR7 binds with high affinity CXCL12 and with lower affinity CXCL11 that is also involved in CXCR3 binding (10). CXCL12/CXCR4 axis controls bone marrow (BM) hematopoietic stem cells (HSCs) trafficking (11). CXCL12 transcript and protein levels change periodically in BM with light/ dark cycles regulating the retention/mobilization in and from BM of CXCR4-positive HSCs; these cells leave BM during sleep when CXCL12 levels are low and return to BM when CXCL12 increases (12). CXCR7 contributes to the circadian oscillations of CXCL12 within BM and to the neutrophils cycles (13). CXCL12/CXCR4/ CXCR7 axis plays a role in cancer regulating cell migration and proliferation, as well as angiogenesis (14). Although molecules targeting CXCR4/CXCR7 have been developed for preclinical and clinical studies in cancer (15), efforts are needed to develop specific and efficient drugs that target both tumor and TME. In this review, we focus on the contribution of the CXCL12/CXCR4/CXCR7 axis in signaling in tumor/TME cells and we evaluate the possible combined targeting of CXCR4 and CXCR7.

\section{CXCL12/CXCR4/CXCR7 AXIS}

CXCR4 is a seven-span transmembrane domains (352 amino acids, $48 \mathrm{kDa}$ ) GPCRs encoded on chromosome $2.1(16,17)$. CXCR4 is considered a key molecule for normal development as the $\mathrm{CXCR}^{-1-}$ knock-out mice die before birth (18). CXCR4 ${ }^{-1-}$ knock-out mice show a very low number of mature $\mathrm{B}$ and $\mathrm{T}$ cells in lymphoid organs and a compromised vascularization in the intestines, stomach, heart and ventricular septal defect that occurs during embryogenesis (19). CXCL12 binding to CXCR4 triggers multiple signal transduction pathways that regulate intracellular calcium flux, chemotaxis, transcription and cell survival (20). CXCL12-CXCR4 forms a complex with the Goi subunit G protein, inhibiting the adenylyl cyclase-mediated cyclic adenosine monophosphate production and promoting mobilization of intracellular calcium. Goi subunit dissociates from G $\beta \gamma$ activating Akt, JNK, MEK and ERK1/2 effectors (21). In addition, $\mathrm{G} \alpha$ subunit activates Ras and Rac/Rho pathways, leading to the phosphorylation of ERK and P38 proteins, respectively. CXCR4 homodimerization results in $\mathrm{G}$ protein independent activation of the JAK/STAT pathway promoting polarization and chemotactic responses (22). When CXCL12 binds CXCR4, the receptor is modified by ubiquitination before the endocytosis and lysosomal degradation. CXCR4 is desensitized by $\mathrm{G}$ proteins uncoupling via GPCR kinase (GRK)-dependent phosphorylation and interaction with $\beta$-arrestin (23). CXCR7 plays a role in the central nervous system (24), angiogenesis (25), neurogenesis (26) and cardiogenesis (27). Although CXCR7 -/knock-out mice show a normal hematopoiesis, they die perinatal due to heart malformation, disturbed lymphangiogenesis and cardiomyocyte hyperplasia (28). Initial studies in zebrafish embryos convincingly show a key role of CXCR7 in progenitor cell migration during embryo- and organo-genesis. CXCR7 sequesters CXCL12 from non-target area permitting the correct CXCR4 positive cell migration (29). Without CXCR7, the required CXCL12 gradient for a directional migration is missing thus the migrating cells still respond to CXCL12 but end in undesirable areas (30). CXCR7, as well as CXCR4, is necessary for the correct migration of interneurons and neuronal development and their subcellular location is different: CXCR4 in the plasma membrane and CXCR7 in intracellular recycling endosomes (31). CXCR7 controls CXCL12 signaling in cortical astrocytes and Schwann cells that also express CXCR4. CXCL12-mediated stimulation of astrocytes activates ERK1/2, Akt but not p38, while in Schwann cells CXCL12 activates p38, ERK1/2 and Akt (32). Studies suggest that CXCR7 internalizes CXCL12 and/or CXCL11 inducing intracellular pathways, such as Akt, MAPkinase (MAPK) and JAK/STAT3, through $\beta$-arrestin (10) or in heterodimers with CXCR4 (33). CXCR4/CXCR7 complex recruits $\beta$-arrestin and activates downstream cell signaling (ERK1/2, p38, SAPK/JNK), inducing cell migration in response to CXCL12 (10). Overall, the CXCR7 signaling relies on cellular context and on relative expression as compared to CXCR4.

\section{ROLE OF CXCL12-CXCR4/CXCR7 IN CANCER}

An active CXCL12/CXCR4 pathway is considered a feature of aggressive tumors (34) as it positively correlates with tumor size (17), grading (16), tumor recurrence $(35,36)$, poor prognosis and patient survival $(17,37,38)$. CXCL12/CXCR4 overexpression has been reported in a wide range of tumors such as prostate, brain, breast, lung, liver, colon, ovary and pancreas (39-42). In breast cancer, CXCR4 overexpression promotes tumor cell dissemination to the lungs and lymph nodes (43) while in melanoma, CXCR4 induces lung metastases but not lymph nodes dissemination (44). In non-small cell lung cancer, high CXCR4 expression enhances cellular motility and invasion via Epidermal Growth Factor Receptors (EGFRs) and Matrix Metallopeptidase 9 (MMP-9) (45). Also CXCR7 is overexpressed in numerous tumors such as liver, cervical, colon, breast, and pancreatic cancer (46). CXCR7 acts on tumor progression and metastases at different levels upon interaction with endogenous ligands, including CXCL12, CXCL11 and the Macrophage Inhibitory Factor (MIF) (13). The protumorigenic activity of CXCR7 is presumably linked to the interplay with membrane receptors such as estrogen receptor (ER) and EGFR $(47,48)$. CXCR4 signaling activates mTOR pathway in pancreatic, gastric and renal cancer (49-51). In 
ovarian cancer, estrogen induces CXCR7 expression that promotes tumor cell migration, invasion and epithelialmesenchymal transition (EMT) through CXCL11 (52) while CXCL12-stimulated EMT depends on CXCR4, suggesting a context-independent contribution of CXCR7 to EMT-signaling (36). CXCR7 mRNA and protein are overexpressed in colorectal cancer patients and correlate to disease stage and distant metastasis (53). In cervical cancer, high CXCR7 independently correlates to shorter disease-specific survival and it is positively associated with larger tumor size and lymph nodes metastasis (54). In lung adenocarcinoma, CXCR7 expression is considered a poor prognostic marker promoting tumor growth and transforming growth factor- $\beta$ (TGF- $\beta$ ) mediated EMT (55). Accordingly, CXCR7 together with CXCR4 predicts worse prognosis in renal cell carcinoma patients (56). Conversely, in rhabdomyosarcoma, CXCR7 expression correlates with a less-metastatic phenotype (57). CXCL12 potentiates CXCR7+/CXCR4+ cancer cell transendothelial migration toward CCL19 and CXCL13, chemokines expressed by ECs in the lymph nodes (58). In addition, CXCR7 inhibition sensitizes cells to chemotherapy or radiation in murine brain tumors (6). In neuroblastoma, CXCR4 and CXCR7 expression are different or even opposed, as CXCR7 is observed in neural-associated compartment of differentiated and matured tumors while CXCR4 in highly aggressive and undifferentiated tumors. CXCR4 favors neuroblastoma diffusion to liver and lungs, whereas CXCR7 promotes liver and adrenal gland dissemination, both CXCR4 and CXCR7 increase BM invasion (59). In breast cancer, CXCR7 overexpression decreases intravasation thus reducing metastasis while enhancing primary tumor growth via angiogenesis (60). Hence, the role of CXCR7 in cancer progression is controversial as some reports suggest pro-metastatic responses and others indicate inhibition of metastasis. The CXCR7-mediated pro-metastatic responses may depend on CXCL11 or on higher receptors availability such as ER (47), EGFR (48) or CXCR4 that significantly contribute to tumor growth and metastasis. CXCR7 regulates CXCR4 surface expression by scavenging CXCL12 (61) or by heterodimerize with CXCR4, reducing CXCR4 internalization and degradation (62), or promoting CXCR4 interactions with intracellular effectors (63). On the other hand, in breast cancer CXCR7 promotes cancer proliferation and angiogenesis but reduces tumor cells intravasation (60). Thus, CXCR7, in the context of high CXCR4, improves chemotaxis to CXCL12 but decreases invasion suppressing CXCL12-induced matrix degradation.

\section{CXCL12-CXCR4/CXCR7 IN THE TUMOR MICROENVIRONMENT}

Tumor-derived chemokines are responsible for recruitment of immunosuppressive cells ( $\mathrm{T}$ regulatory cells (Tregs), myeloid derived suppressor cells (MDSCs), and dendritic cells (DCs) to the tumor niche (64). CXCL12 has an anti-inflammatory role by mediating $\mathrm{T}$ cell polarization towards Tregs $(65,66)$, generating poor functional DCs, and macrophages expressing proangiogenic factors (31). In prostate cancer, high stromal TGF- $\beta$ induces
CXCR4 and activates Akt through stromal CXCL12, thus abrogating the growth-inhibitory responses to TGF- $\beta$ (67). CXCL12/CXCR4 axis promotes migration and survival of MDSCs in osteosarcoma inhibiting cytotoxic T cell (CTL) expansion and thus controlling tumor growth (68). CXCR7 is highly expressed by tumor associated blood vessels of melanoma, breast and lung cancers, but not by normal vasculature (69). In tumor vascular endothelium, CXCR7 promotes breast, prostate and lung cancer invasive and migratory capability (70). CXCR7 protein is detected in human secondary lymphoid organ-derived B cells, natural killer (NK), basophil and DCs $(71,72)$. CXCR7 has been reported on CD4+ T cells but not on CD8+ T cells (71). CXCR7 is expressed by lymphocytes and granulocytes in BM and by monocytes, granulocytes, and platelets in peripheral blood. Interestingly, these cells fail to express CXCR7 when isolated from umbilical cord blood (73). In breast cancer, CXCR7 modulates TME-recruiting M2 macrophages through macrophage colony-stimulating factor (M$\mathrm{CSF} /$ macrophage colony-stimulating factor receptor (MCSF-R) pathway, enhancing tumor growth and metastasis (74). CXCR7/ CXCR4 heterodimers promote Monocytic-MDSC (M-MDSCs) and M2-like macrophages in colon cancer turning the TME toward immunosuppression (75). CXCL12/CXCR4/CXCR7 crosstalk in TME is illustrated in Figure 1.

\section{CXCR4 AND CXCR7 IN ENDOTHELIAL CELLS}

In hepatocellular carcinoma (HCC), CXCR4 is expressed in tumor endothelium sprouting tumor vessels (76) and CXCR4-positive ECs predict sorafenib susceptibility. Monocytes/macrophages-TNF- $\alpha$ induces CXCR4 expression on ECs via Raf-ERK pathway (77). CXCR7 expression, low in the endothelium, is upregulated during inflammation by pro-inflammatory cytokines such as IL-8 (78) or IL-1b (79), by lipopolysaccharide (80) or during infection by oncoviruses (46). CXCR7 is expressed by ECs and tumor endothelial cells (TECs) promoting their migration (81) and survival (82). It is specifically up-regulated by TNF- $\alpha$ treated/ inflamed ECs $(83,84)$ and is strongly induced by hypoxiainducible factor-1 alpha (HIF-1 $\alpha$ ) (85). CXCL12 secreted by TECs, compared to normal endothelial cells (NECs), promotes CXCR7-mediated angiogenesis via ERK1/2 suggesting an autocrine/paracrine loop between tumor and TECs (83). Thus, CXCR7 is a promising target for vascular targeted therapies due to its restricted expression and the concomitant effects on leukocytes (e.g., inhibition of immune suppressive Tregs). In contrast, knockout mice with selective depletion of CXCR7 in vascular ECs present more spontaneous lung metastases in "in vivo" breast cancer model, indicating that CXCR7 by sequestration of CXCL12 could limit cancer metastases development (86).

\section{CXCR4 AND CXCR7 IN DENDRITIC CELLS}

DCs are the most potent antigen presenting cells (APCs) in the immune system (87). Immature DCs (iDCs) express CXCR4 to 


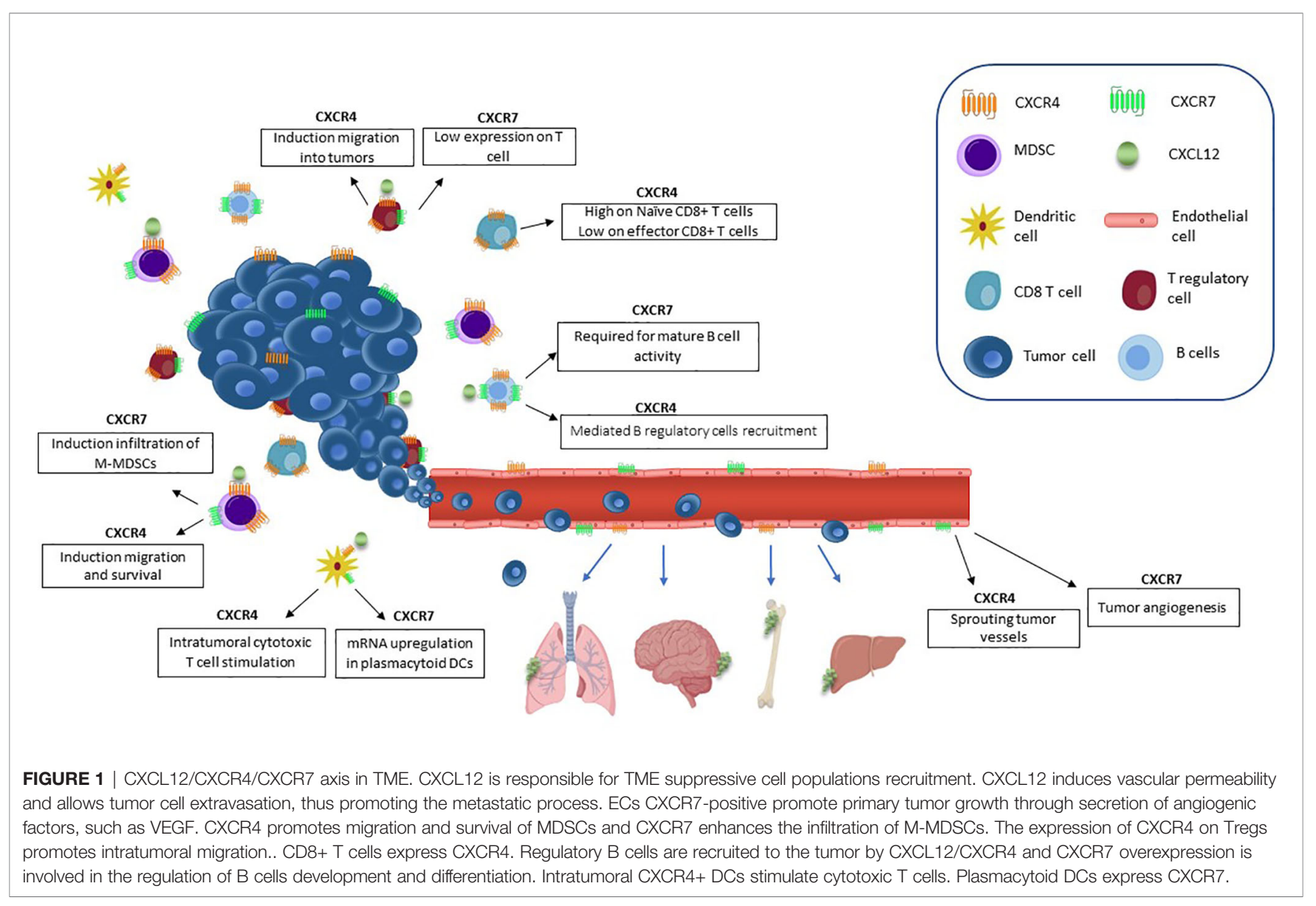

reach inflamed peripheral tissues (88). CXCR4 retains pre-DCs in the BM, CCR2 and CX3CR1 direct migration of pre-DCs to the lung at steady state while CCR2 controls inflammationdirected pre-DCs migration (89). CXCR4 is important for DCs survival, as CXCR4 antagonism reduces mature murine bone marrow-derived DCs (BMDCs) and Langerhans cells (LCs) (90). Plasmacytoid dendritic cells (pDC) secrete type I interferon in response to pathogens while RNA viral natural monoamines/ synthetic amines inhibits pDC activation engaging CXCR4 (91). Although CXCR7 mRNA is upregulated in pDCs, it does not correlate with surface protein (71).

\section{CXCR4 AND CXCR7 IN T-REGULATORY CELLS}

Tregs $\left(\mathrm{CD} 4^{+} \mathrm{CD} 25^{\text {high }}\right.$ FoxP3 $\left.3^{+}\right)$are $\mathrm{CD} 4+\mathrm{T}$ cells with predominantly suppressive activity (5-10\% of circulating $\mathrm{CD}^{+}$ $\mathrm{T}$ cells in humans). Tregs impair immune effector cells function via cytokines, direct lysis, inhibitory receptors, metabolic disruption, IL-2 depletion or inducing an immunosuppressive microenvironment $(92,93)$. Tregs overexpress CXCR4 in advanced cervical cancer (94), malignant pleural mesothelioma (95), ovarian cancer (92) and renal cell carcinoma $(96,97)$.
CXCR4 expression on Tregs correlates with prognosis in ovarian (98), pancreatic (99) and liver cancer (100), or it may not correlate with patient outcome $(93,101)$. CXCL12 secreted by mesotheliomas attracts CXCR4-positive Foxp $3^{+} \mathrm{CD} 25^{+} \mathrm{T}$ cell and is associated with the inflammatory response to these tumors (95). HIF pathway promotes Tregs immunosuppressive function through the expression of their lineage transcriptional regulator FOXP3. In the CXCR4-positive Tregs, tumoral CXCL12 enhances recruitment and suppresses the anti-tumor immune response in basal-like breast cancer (102). CXCR7 is minimally detected but functional on the surface of T cells (69).

\section{CXCR4 AND CXCR7 IN CD8 T CELLS}

CD8+ T cells positively correlate with good prognosis in breast, colorectal, glioblastoma and cervical cancers. In TME, naïve $\mathrm{CD}^{+} \mathrm{T}$ cells are differentiated into effector CD8+ $\mathrm{T}$ cells and further differentiated into cytotoxic and memory CD8+ T cells (103). CXCR4 is highly expressed in BM on both naive and memory CD8+ T cells where regulates homing to the BM in mice (104). CXCR4 in CD8+ $\mathrm{T}$ cells $\left(\mathrm{T}^{\mathrm{CXCR} 4}\right)$ potentiates migration toward vascular-associated CXCL12-positive cells in the BM. In lymphoma-bearing mice, $\mathrm{T}^{\mathrm{CXCR} 4}$ potentiates the effector 
function increasing tumor protection (105). In fresh human pancreatic ductal adenocarcinoma (PDAC) slices treated with programmed cell death protein 1 (PD-1) and CXCR4 blockers, CD8+ T cells expansion and apoptosis is detected (106). CD8+ T cells do not express CXCR7 receptor (71).

\section{CXCR4 AND CXCR7 IN B CELLS}

Relatively few B cells are usually found in tumor infiltrates (107). Recent data show that tumor B and plasma cells may exert both pro-tumor and anti-tumor effects depending on the TME, phenotypes of $\mathrm{B}$ cells and the relative antibodies production. CXCR4 is expressed at all stages of B cell development in BM from HSCs to mature B cells and plays a major role in the homing of B cell precursors (108). CXCR4 is necessary for developing B cells in the BM but not for mature B cells (109). CXCR4-positive mature $\mathrm{B}$ cells home to the $\mathrm{BM}$ niche, completing their maturation and staying in contact with CXCL12-expressing BM stromal cells (110). CXCL12/CXCR4 mediates the B regulatory cells recruitment to the tumor inhibiting $\mathrm{T}$ cell activity (111). In a spontaneous lymph node metastasis murine breast cancer model, primary tumors induce B cell accumulation in draining lymph nodes. B cells selectively promote lymph node metastasis through pathogenic IgG production that activates the HSPA4-binding protein ITGB5 and the Src/NF- $\kappa \mathrm{B}$ pathway in tumor cells for CXCR4/SDF1 $\alpha$-axismediated metastasis (112). CXCR7 is expressed in mature B cells and is involved in the regulation of their development and differentiation (69), specifically it is highly restricted to marginal zone B cells and its deletion or CXCR7 specific inhibition, reduces marginal zone $\mathrm{B}$ cell numbers and disrupts splenic marginal zone architecture (113). CpG-activated pDCs downregulate CXCR7 expression on primary B cells. CXCR7 expression is required for mature $B$ cells and for the survival and differentiation of the switch memory components, being expressed only in cells that produce antibodies (71). CXCR7 overexpression in Mesenchymal Stem Cells (MSCs) could stimulate regulatory B cells. B cells may negatively regulate tumor immunity and promote tumor progression via IL-10 and TGF- $\beta$ expression (114).

\section{TARGETING THE CXCL12/CXCR4/CXCR7 AXIS IN COMBINATION THERAPY}

The only approved drug CXCR4 inhibitor is AMD3100 (known as Plerixafor or Mozobil) (115) while multiple antagonists are in different stages of development. CXCR4 antagonists on the field are: (i) modified peptides (BL8040, Balixafortide, FC131); (ii) smallmolecules CXCR4 antagonists (AMD3100, AMD11070, MSX-122, GSK812397); (iii) CXCL12 peptide analogs (CTCE-9908, NOXA12); or (iv) antibodies (MDX-1338/BMS 93656, ALX-0651). BL8040 promotes infiltration of effector $\mathrm{T}$ cells and decreases the number of immune suppressor cells (116). BL-8040 plus the anti PD-1, pembrolizumab, in the COMBAT trial demonstrates that effector $\mathrm{T}$ cells potentiate the benefit of chemotherapy in pancreatic ductal adenocarcinoma (PDAC) patients (117). In ovarian cancer, a novel oncolytic vaccinia virus expressing a CXCR4 antagonist (OVV-CXCR4-A-Fc), in combination with DCs pulsed with tumor lysates, can modulate TME by reducing immunosuppressive elements with higher spontaneous antitumor immunity (118). Balixafortide (POL6326) is a cyclic peptide CXCR4 antagonist that effectively mobilizes HSCs. Balixafortide treatment versus eribulin is currently being evaluated in a phase 3 trial after the objective response of balixafortide plus eribulin in the treatment of metastatic Her-negative breast cancers (119). Table 1 lists CXCR4 inhibitors in clinical development. In contrast to CXCR4 antagonists, there are only few studies describing CXCR7 inhibitors. CCX771 (ChemoCentryx) induces $\beta$-arrestin recruitment to the receptor (120), inhibits tumor growth, lung metastasis and tumor angiogenesis in vivo (83). In prostate cancer models, CCX771 plus the androgen blocker enzalutamide significantly suppresses tumor growth probably due to low proangiogenic signaling (121). Other analogues have been developed with various pharmacological profiles, including the partial agonist CCX777 (122) or CCX733 (ChemoCentryx) which has been reported to act as CXCR7 antagonist (123). The antibody 89Zrlabeled 11G8 is able to detect CXCR7 in mice xenografted with human breast, lung and oesophageal cancers, suggesting that CXCR7 is a viable diagnostic marker (124). Recently, an antiCXCR7 single chain antibody (X7Ab) with a human immunoglobulin G1 (IgG1) Fc sequence has been described (84). It binds to the same site on the receptor as CXCL12 and inhibits CXCL12-mediated receptor activation. It engages anti-tumor immune response through Fc-driven antibody dependent cell cytotoxicity (ADCC) and antibody-dependent cellular phagocytosis (ADCP) in glioblastoma U343, U251X7, and GL261 cells and, in combination with the temozolomide, significantly reduces glioblastoma progression. Interestingly, commonly prescribed medications atorvastatin and pioglitazone have been shown to decrease CXCR7 expression via cholesterol synthesis and peroxisome proliferator-activated receptor (PPAR) $-\gamma$ respectively, particularly in macrophages (125). Some antagonists could bind both receptors, others bind exclusively CXCR4 or CXCR7 acting as antagonists and/or partial agonist. AMD3100, a CXCR4 antagonist, acts as partial agonist for CXCR7 (126). The cyclic peptidomimetic TC14012 provides therapeutic advantage targeting the CXCR4-CXCL12 axis in chronic lymphocytic leukemia (CLL) while it behaves as CXCR7 agonist in glioma cells (127). A CXCR4 ECL2-based peptide also inhibits CXCR7 internalization (128). Peptide ECL2-X4 displays anti-HIV properties towards CXCR4-using viruses blocking CXCL12 interactions with both CXCR4 and CXCR7.

\section{TARGETING CXCL12/CXCR4/CXCR7 AXIS IN COMBINATION WITH IMMUNE CHECKPOINTS INHIBITORS (ICIs)}

Recently, CXCR4 antagonists have been coupled to ICIs with the intent to remodel TME improving ICIs efficacy (129). Since the initiation of immune checkpoint cascades, such as PD-1 
TABLE 1 | CXCR4 antagonists in clinical development.

\begin{tabular}{|c|c|c|c|c|}
\hline Drug Name & Phase & Active Indication & Combination Therapy & Trial number \\
\hline \multirow[t]{4}{*}{ Plerixafor (AMD3100) } & Phase 3 & Myelokathexis & & NCT02231879 \\
\hline & Phase 2 & Metastasis Pancreatic Cancer & Cemiplimab & NCT4177810 \\
\hline & Phase 2 & $\begin{array}{l}\text { Wiskott-Aldrich Syndrome, Hematopoietic Stem Cell } \\
\text { Transplantation }\end{array}$ & & NCT3019809 \\
\hline & Phase 2 & Acute Myeloid Leukemia, Acute Lymphoid Leukemia & Busulfan, Cyclophosphamide & NCT2065460 \\
\hline & Phase 1 & Melanoma & Pembrolizumab & NCT02823405 \\
\hline & Phase $1 / 2$ & Renal Cancer & axitinib & NCT02667886 \\
\hline USL311 & Phase $1 / 2$ & Solid Tumors (Phase 1), Relapsed/Recurrent GBM (Phase 2) & Lomustine & NCT02765165 \\
\hline NOX-A12 & Phase $1 / 2$ & $\begin{array}{l}\text { Metastatic Colorectal Cancer } \\
\text { Metastatic Pancreatic Cancer }\end{array}$ & Pernbrolizurnab & NCT03168139 \\
\hline CX-01 & Phase 1 & $\begin{array}{l}\text { Myelodysplastic Syndromes, } \\
\text { Acute Myeloid Leukemia }\end{array}$ & Azacitidine & NCT02995655 \\
\hline \multirow[t]{2}{*}{ [68Ga]Pentixafor } & Phase 1 & Neuroendocrine Tumors & & NCT03335670 \\
\hline & $\begin{array}{l}\text { Early } \\
\text { Phase }\end{array}$ & Multiple MyelomaLymphoma & & NCT03436342 \\
\hline \multirow[t]{4}{*}{ BL-8040 } & Phase 2 & $\begin{array}{l}\text { Metastatic Pancreatic } \\
\text { Adenocarcinorm }\end{array}$ & Pernbrolizurnab & NCT02826486 \\
\hline & Phase 2 & $\begin{array}{l}\text { Malignant Neoplasms of Digestive OrgansMetastatic Pancreatic } \\
\text { Cancer }\end{array}$ & Pernbrolizurnab & NCT02907099 \\
\hline & Phase 3 & Multiple Myeloma & & NCT03246529 \\
\hline & Phase 1/2 & Pancreatic Adenocarcinorm & $\begin{array}{l}\text { PEGPH20, Cobimetinib, } \\
\text { Atezolizumab, Gemcitabine, Nab- } \\
\text { Paclitaxet Oxaliplatin, Leucovorin, } \\
\text { Fluorouracil }\end{array}$ & NCT03193190 \\
\hline \multicolumn{5}{|l|}{ Anti-CXCR4 antibodies } \\
\hline \multirow[t]{2}{*}{$\begin{array}{l}\text { Uloccuplumab (MDX- } \\
\text { 1338) }\end{array}$} & Phase 1/2 & $\begin{array}{l}\text { Waldenstrom's } \\
\text { Macroglobulinemia }\end{array}$ & Ibtutinib & NCT03225716 \\
\hline & Phase 1/2 & Leukemia & Cytarabine & NCT02305563 \\
\hline ALX-0651 & Phase 1 & Healthy Volunteers & & NCT01374503 \\
\hline PF-06747143 & Phase 1 & Acute Myeloid Leukemia & $\begin{array}{l}\text { Cytarabine, Daunorubicin, } \\
\text { Azacitidine, } \\
\text { Decitabine }\end{array}$ & NCT02954653 \\
\hline
\end{tabular}

signaling cascade, leads to immune evasion, treatment with ICIs can activate $\mathrm{T}$ cells response and enable the immune cells to target tumor cells (130). The lack of immune effector cells, the presence of immune suppressive cells and the polarization of immune cells in the TME play a fundamental role in shifting the balance from an immune active 'hot' or 'T-cell-inflamed TME' to 'cold' TME or 'non-T-cell-inflamed TME', such as those from the prostate and pancreas $(131,132)$. 'Hot tumors' are identified by infiltration of $\mathrm{T}$ cells and molecular immune activation (133, 134). Chemokines and chemokine receptors represent valuable targets for optimizing antitumor immune responses. In the leukemic hematopoietic microenvironment (LHME) in MLLAF9-induced mouse acute myeloid leukemia (AML) model, CCL3-CCR1/CCR5 and CXCL12-CXCR4 inhibition block leukemia progression by impairing Tregs migration (135). Combinatorial blockade of CXCR4 and PD-1 reduces Tregs and MDSCs recruitment within the immunosuppressive TME promoting tumor-specific cell-mediated immune responses in ovarian cancer (136). Moreover, CXCR4 blocking inhibits PD-1 expression on CD8+ $\mathrm{T}$ cells and promotes the conversion of Tregs into $\mathrm{CD} 4^{+} \mathrm{CD} 25^{-} \mathrm{Foxp}^{+} \mathrm{IL}^{+} \mathrm{CD} 40 \mathrm{~L}^{+}$helper-like cells (137). Inhibition of CXCR4 with AMD3100 decreases 
desmoplasia, reduces immunosuppression, and improves $\mathrm{T}$ cell infiltration and response to ICIs in breast cancer (138) while targeting PD-1 and CXCR4 potentiates anti PD-1 efficacy in murine immune sensitive and immune resistant tumors (139). A nanocomplex of CXCR4 antagonist-paclitaxel-loaded has been developed for pulmonary delivery of anti- programmed deathligand 1 (PD-L1) small interfering RNA (siPD-L1). The nanocomplex promotes $\mathrm{T}$ cell infiltration, decreases alphasmooth muscle actin ( $\alpha$-SMA) and collagen, reduces MDSCs and Tregs recruitment (140). Thus, considering CXCR4 and CXCR7 crosstalk in immune cells within the tumor microenvironment, some mechanisms underlying tumor resistance to immunotherapy may be impaired targeting the CXCR4/CXCR7-CXCL12 axis.

\section{DISCUSSION AND CONCLUSIONS}

Immuno-resistance and vascularization are acquired tumor features that contribute to cancer growth and metastasis. Among the different signaling pathways, directly or indirectly involved in cancer immune-resistance and angiogenesis, CXCR4/CXCR7/CXCL12 is crucial for participating in cancer migration, angiogenesis and immunosuppressive cell recruitment. Thus, the inhibition of the CXCR4/CXCL12 or CXCR7/CXCL12 axis is attractive in cancers overexpressing both receptors such as colorectal cancer (15), renal cancer (51) or glioblastoma (30). Since several CXCR4 antagonists, including

\section{REFERENCES}

1. Mollica Poeta V, Massara M, Capucetti A, Bonecchi R. Chemokines and Chemokine Receptors: New Targets for Cancer Immunotherapy. Front Immunol (2019) 10:379. doi: 10.3389/fimmu.2019.00379

2. Choi J, Selmi C, Leung PS, Kenny TP, Roskams T, Gershwin ME. Chemokine and chemokine receptors in autoimmunity: the case of primary biliary cholangitis. Expert Rev Clin Immunol (2016) 12(6):66172. doi: 10.1586/1744666x.2016.1147956

3. Marcuzzi E, Angioni R, Molon B, Calì B. Correction: Marcuzzi, E., et al. Chemokines and Chemokine Receptors: Orchestrating Tumor Metastasization. Int J Mol Sci (2019) 20, 96. Int J Mol Sci 20(11). doi: 10.3390/ijms20112651

4. Sanchez J, Lane JR, Canals M, Stone MJ. Influence of Chemokine NTerminal Modification on Biased Agonism at the Chemokine Receptor CCR1. Int J Mol Sci (2019) 20(10):2417. doi: 10.3390/ijms20102417

5. Bonecchi R, Graham GJ. Atypical Chemokine Receptors and Their Roles in the Resolution of the Inflammatory Response. Front Immunol (2016) 7:224. doi: 10.3389/fimmu.2016.00224

6. Salazar N, Zabel BA. Support of Tumor Endothelial Cells by Chemokine Receptors. Front Immunol (2019) 10:147. doi: 10.3389/fimmu.2019.00147

7. García-Cuesta EM, Santiago CA, Vallejo-Díaz J, Juarranz Y, RodríguezFrade JM, Mellado M. The Role of the CXCL12/CXCR4/ACKR3 Axis in Autoimmune Diseases. Front Endocrinol (Lausanne) (2019) 10:585. doi: 10.3389/fendo.2019.00585

8. Meng W, Xue S, Chen Y. The role of CXCL12 in tumor microenvironment. Gene (2018) 641:105-10. doi: 10.1016/j.gene.2017.10.015

9. Neves M, Fumagalli A, van den Bor J, Marin P, Smit MJ, Mayor F. The Role of ACKR3 in Breast, Lung, and Brain Cancer. Mol Pharmacol (2019) 96 (6):819-25. doi: 10.1124/mol.118.115279

10. Singh AK, Arya RK, Trivedi AK, Sanyal S, Baral R, Dormond O, et al. Chemokine receptor trio: CXCR3, CXCR4 and CXCR7 crosstalk via peptides, small molecules and antibodies, have been developed and considered for clinical development, the identification of agents able to efficiently block the CXCL12/CXCR7 pathway is still ongoing. However, the observation that CXCR4 inhibition could only partially block the responsiveness of tumor/TME cells to CXCL12 gradients, has questioned the effective role of the exclusive CXCR4/CXCL12 or CXCR7/CXCL12 interaction during cancer progression. CXCL12 inhibitors, such as NOX012 (141), neutralizing CXCL12 nanobodies (142), or chalcone 4 derivate LIT-927 (143), may affect both CXCR4 and CXCR7 signaling. Unfortunately, the blockage of CXCL12 cannot interfere with CXCR7 signaling mediated by ligands different from CXCL12, such as CXCL11, or cannot provide CXCR4/ CXCR7 co-expression, crosstalk and heterodimerization. Thus, despite possible opposite effects should be considered during the design of combination therapies, the administration of antagonists of CXCR4/CXCR7 could offer a valid therapeutic option as a stand-alone therapy or in combination with current immunotherapies.

\section{AUTHOR CONTRIBUTIONS}

$\mathrm{SSa}, \mathrm{CI}$, and SSc contributed in conception and design of the study. AMT, AC, FA, and GG supervised the study. SSa, CI, and SSc wrote and edited the manuscript. SSa and CI equally contributed. All authors contributed to the article and approved the submitted version.

CXCL11 and CXCL12. Cytokine Growth Factor Rev (2013) 24(1):41-9. doi: 10.1016/j.cytogfr.2012.08.007

11. Zhang Y, Saavedra E, Tang R, Gu Y, Lappin P, Trajkovic D, et al. Targeting primary acute myeloid leukemia with a new CXCR4 antagonist IgG1 antibody (PF-06747143). Sci Rep (2017) 7(1):7305. doi: 10.1038/s41598017-07848-8

12. Méndez-Ferrer S, Michurina TV, Ferraro F, Mazloom AR, Macarthur BD, Lira SA, et al. Mesenchymal and haematopoietic stem cells form a unique bone marrow niche. Nature (2010) 466(7308):829-34. doi: 10.1038/nature09262

13. Koenen J, Bachelerie F, Balabanian K, Schlecht-Louf G, Gallego C. Atypical Chemokine Receptor 3 (ACKR3): A Comprehensive Overview of its Expression and Potential Roles in the Immune System. Mol Pharmacol (2019) 96(6):809-18. doi: 10.1124/mol.118.115329

14. Huynh C, Dingemanse J, Meyer ZuSchwabedissen HE, Sidharta PN. Relevance of the CXCR4/CXCR7-CXCL12 axis and its effect in pathophysiological conditions. Pharmacol Res (2020) 161:105092. doi: 10.1016/j.phrs.2020.105092

15. Shi Y, Riese DJ, Shen J. The Role of the CXCL12/CXCR4/CXCR7 Chemokine Axis in Cancer. Front Pharmacol (2020) 11:574667. doi: 10.3389/fphar.2020.574667

16. Ding Y, Du Y. Clinicopathological significance and prognostic role of chemokine receptor CXCR4 expression in pancreatic ductal adenocarcinoma, a meta-analysis and literature review. Int J Surg (2019) 65:32-8. doi: 10.1016/j.ijsu.2019.03.009

17. Yang J, Zhang L, Jiang Z, Ge C, Zhao F, Jiang J, et al. TCF12 promotes the tumorigenesis and metastasis of hepatocellular carcinoma via upregulation of CXCR4 expression. Theranostics (2019) 9(20):5810-27. doi: 10.7150/ thno. 34973

18. Kawaguchi N, Zhang T, Nakanishi T. Involvement of CXCR4 in Normal and Abnormal Development. Cells (2019) 8(2):185. doi: 10.3390/cells8020185

19. Vlahakis SR, Villasis-Keever A, Gomez T, Vanegas M, Vlahakis N, Paya CV. $\mathrm{G}$ protein-coupled chemokine receptors induce both survival and apoptotic 
signaling pathways. J Immunol (2002) 169(10):5546-54. doi: 10.4049/ jimmunol.169.10.5546

20. Bianchi ME, Mezzapelle R. The Chemokine Receptor CXCR4 in Cell Proliferation and Tissue Regeneration. Front Immunol (2020) 11:2109. doi: $10.3389 /$ fimmu. 2020.02109

21. Teicher BA, Fricker SP. CXCL12 (SDF-1)/CXCR4 pathway in cancer. Clin Cancer Res (2010) 16(11):2927-31. doi: 10.1158/1078-0432.Ccr-09-2329

22. Chatterjee $S$, Behnam AB, Nimmagadda $S$. The intricate role of CXCR4 in cancer. Adv Cancer Res (2014) 124:31-82. doi: 10.1016/b978-0-12-4116382.00002-1

23. Marchese A. Endocytic trafficking of chemokine receptors. Curr Opin Cell Biol (2014) 27:72-7. doi: 10.1016/j.ceb.2013.11.011

24. Chu T, Shields LBE, Zhang YP, Feng S, Shields CB, Cai J. CXCL12/CXCR4/ CXCR7 Chemokine Axis in the Central Nervous System: Therapeutic Targets for Remyelination in Demyelinating Diseases. Neuroscientist (2017) 23(6):627-48. doi: 10.1177/1073858416685690

25. Zhang M, Qiu L, Zhang Y, Xu D, Zheng JC, Jiang L. CXCL12 enhances angiogenesis through CXCR7 activation in human umbilical vein endothelial cells. Sci Rep (2017) 7(1):8289. doi: 10.1038/s41598-017-08840-y

26. Kremer D, Cui QL, Göttle P, Kuhlmann T, Hartung HP, Antel J, et al. CXCR7 Is Involved in Human Oligodendroglial Precursor Cell Maturation. PloS One (2016) 11(1):e0146503. doi: 10.1371/journal.pone.0146503

27. Ceholski DK, Turnbull IC, Pothula V, Lecce L, Jarrah AA, Kho C, et al. CXCR4 and CXCR7 play distinct roles in cardiac lineage specification and pharmacologic $\beta$-adrenergic response. Stem Cell Res (2017) 23:77-86. doi: 10.1016/j.scr.2017.06.015

28. Yu S, Crawford D, Tsuchihashi T, Behrens TW, Srivastava D. The chemokine receptor CXCR7 functions to regulate cardiac valve remodeling. Dev Dyn (2011) 240(2):384-93. doi: 10.1002/dvdy.22549

29. Graham GJ, Locati M, Mantovani A, Rot A, Thelen M. The biochemistry and biology of the atypical chemokine receptors. Immunol Lett (2012) 145(12):30-8. doi: 10.1016/j.imlet.2012.04.004

30. Würth R, Bajetto A, Harrison JK, Barbieri F, Florio T. CXCL12 modulation of CXCR4 and CXCR7 activity in human glioblastoma stem-like cells and regulation of the tumor microenvironment. Front Cell Neurosci (2014) 8:144. doi: $10.3389 /$ fncel.2014.00144

31. Sanchez-Alcaniz JA, Haege S, Mueller W, Pla R, Mackay F, Schulz S, et al. Cxcr7 controls neuronal migration by regulating chemokine responsiveness. Neuron (2011) 69(1):77-90. doi: 10.1016/j.neuron.2010.12.006

32. Odemis V, Boosmann K, Heinen A, Küry P, Engele J. CXCR7 is an active component of SDF-1 signalling in astrocytes and Schwann cells. J Cell Sci (2010) 123(Pt 7):1081-8. doi: 10.1242/jcs.062810

33. Hattermann K, Mentlein R. An infernal trio: the chemokine CXCL12 and its receptors CXCR4 and CXCR7 in tumor biology. Ann Anat (2013) 195 (2):103-10. doi: 10.1016/j.aanat.2012.10.013

34. Liu XQ, Fourel L, Dalonneau F, Sadir R, Leal S, Lortat-Jacob H, et al. Biomaterial-enabled delivery of SDF- $1 \alpha$ at the ventral side of breast cancer cells reveals a crosstalk between cell receptors to promote the invasive phenotype. Biomaterials (2017) 127:61-74. doi: 10.1016/ j.biomaterials.2017.02.035

35. Wald O. CXCR4 Based Therapeutics for Non-Small Cell Lung Cancer (NSCLC). J Clin Med (2018) 7(10):303. doi: 10.3390/jcm7100303

36. Zheng N, Liu W, Chen J, Li B, Liu J, Wang J, et al. CXCR7 is not obligatory for CXCL12-CXCR4-induced epithelial-mesenchymal transition in human ovarian cancer. Mol Carcinog (2019) 58(1):144-55. doi: 10.1002/mc.22916

37. Coniglio SJ. Role of Tumor-Derived Chemokines in Osteolytic Bone Metastasis. Front Endocrinol (Lausanne) (2018) 9:313. doi: 10.3389/ fendo.2018.00313

38. Shanmugam MK, Ahn KS, Hsu A, Wo CC, Yuan Y, Tan KHB, et al. Thymoquinone Inhibits Bone Metastasis of Breast Cancer Cells Through Abrogation of the CXCR4 Signaling Axis. Front Pharmacol (2018) 9:1294. doi: 10.3389/fphar.2018.01294

39. Li M, Lu Y, Xu Y, Wang J, Zhang C, Du Y, et al. Horizontal transfer of exosomal CXCR4 promotes murine hepatocarcinoma cell migration, invasion and lymphangiogenesis. Gene (2018) 676:101-9. doi: 10.1016/ j.gene.2018.07.018

40. Mushtaq M, Jensen L, Davidsson S, Grygoruk OV, Andrén O, Kashuba V, et al. The MRPS18-2 protein levels correlate with prostate tumor progression and it induces CXCR4-dependent migration of cancer cells. Sci Rep (2018) 8 (1):2268. doi: 10.1038/s41598-018-20765-8

41. Perrot-Applanat M, Vacher S, Pimpie C, Chemlali W, Derieux S, Pocard M, et al. Differential gene expression in growth factors, epithelial mesenchymal transition and chemotaxis in the diffuse type compared with the intestinal type of gastric cancer. Oncol Lett (2019) 18(1):674-86. doi: 10.3892/ ol.2019.10392

42. Truong D, Fiorelli R, Barrientos ES, Melendez EL, Sanai N, Mehta S, et al. A three-dimensional (3D) organotypic microfluidic model for glioma stem cells - Vascular interactions. Biomaterials (2019) 198:63-77. doi: 10.1016/ j.biomaterials.2018.07.048

43. Xu C, Zhao H, Chen H, Yao Q. CXCR4 in breast cancer: oncogenic role and therapeutic targeting. Drug Des Devel Ther (2015) 9:4953-64. doi: 10.2147/ dddt.S84932

44. Murakami T, Maki W, Cardones AR, Fang H, Tun Kyi A, Nestle FO, et al. Expression of CXC chemokine receptor-4 enhances the pulmonary metastatic potential of murine B16 melanoma cells. Cancer Res (2002) 62(24):7328-34.

45. Zuo J, Wen M, Li S, Lv X, Wang L, Ai X, et al. Overexpression of CXCR4 promotes invasion and migration of non-small cell lung cancer via EGFR and MMP-9. Oncol Lett (2017) 14(6):7513-21. doi: 10.3892/ol.2017.7168

46. Freitas C, Desnoyer A, Meuris F, Bachelerie F, Balabanian K, Machelon V. The relevance of the chemokine receptor ACKR3/CXCR7 on CXCL12mediated effects in cancers with a focus on virus-related cancers. Cytokine Growth Factor Rev (2014) 25(3):307-16. doi: 10.1016/j.cytogfr.2014.04.006

47. Hao M, Weng X, Wang Y, Sun X, Yan T, Li Y, et al. Targeting CXCR7 improves the efficacy of breast cancer patients with tamoxifen therapy. Biochem Pharmacol (2018) 147:128-40. doi: 10.1016/j.bcp.2017.11.013

48. Salazar N, Muñoz D, Kallifatidis G, Singh RK, Jordà M, Lokeshwar BL, The chemokine receptor CXCR7 interacts with EGFR to promote breast cancer cell proliferation. Mol Cancer (2014) 13:198. doi: 10.1186/1476-459813-198

49. Weekes CD, Song D, Arcaroli J, Wilson LA, Rubio-Viqueira B, Cusatis G, et al. Stromal cell-derived factor $1 \alpha$ mediates resistance to mTOR-directed therapy in pancreatic cancer. Neoplasia (2012) 14(8):690-701. doi: 10.1593/ neo. 111810

50. Fujita T, Chiwaki F, Takahashi R, Aoyagi K, Yanagihara K, Nishimura T, et al. Identification and Characterization of CXCR4-Positive Gastric Cancer Stem Cells. PloS One (2015) 10(6):e0130808. doi: 10.1371/ journal.pone. 0130808

51. Ieranò C, Santagata S, Napolitano M, Guardia F, Grimaldi A, Antignani E, et al. CXCR4 and CXCR7 transduce through mTOR in human renal cancer cells. Cell Death Dis (2014) 5(7):e1310. doi: 10.1038/cddis.2014.269

52. Benhadjeba S, Edjekouane L, Sauvé K, Carmona E, Tremblay A. Feedback control of the CXCR7/CXCL11 chemokine axis by estrogen receptor $\alpha$ in ovarian cancer. Mol Oncol (2018) 12(10):1689-705. doi: 10.1002/18780261.12362

53. Yang D, Dai T, Xue L, Liu X, Wu B, Geng J, et al. Expression of chemokine receptor CXCR7 in colorectal carcinoma and its prognostic significance. Int $J$ Clin Exp Pathol (2015) 8(10):13051-8.

54. Schrevel M, Karim R, ter Haar NT, van der Burg SH, Trimbos JB, Fleuren GJ, et al. CXCR7 expression is associated with disease-free and disease-specific survival in cervical cancer patients. Br J Cancer (2012) 106(9):1520-5. doi: 10.1038/bjc.2012.110

55. Wu YC, Tang SJ, Sun GH, Sun KH. CXCR7 mediates TGFß1-promoted EMT and tumor-initiating features in lung cancer. Oncogene (2016) 35 (16):2123-32. doi: 10.1038/onc.2015.274

56. D'Alterio C, Consales C, Polimeno M, Franco R, Cindolo L, Portella L, et al. Concomitant CXCR4 and CXCR7 expression predicts poor prognosis in renal cancer. Curr Cancer Drug Targets (2010) 10(7):772-81. doi: 10.2174/ 156800910793605839

57. Massara M, Bonavita O, Mantovani A, Locati M, Bonecchi R. Atypical chemokine receptors in cancer: friends or foes? J Leukoc Biol (2016) 99 (6):927-33. doi: 10.1189/jlb.3MR0915-431RR

58. Zabel BA, Lewén S, Berahovich RD, Jaén JC, Schall TJ. The novel chemokine receptor CXCR7 regulates trans-endothelial migration of cancer cells. Mol Cancer (2011) 10:73. doi: 10.1186/1476-4598-10-73

59. Mühlethaler-Mottet A, Liberman J, Ascenção K, Flahaut M, Balmas Bourloud $\mathrm{K}$, Yan P, et al. The CXCR4/CXCR7/CXCL12 Axis Is Involved in a Secondary 
but Complex Control of Neuroblastoma Metastatic Cell Homing. PloS One (2015) 10(5):e0125616. doi: 10.1371/journal.pone.0125616

60. Hernandez L, Magalhaes MA, Coniglio SJ, Condeelis JS, Segall JE. Opposing roles of CXCR4 and CXCR7 in breast cancer metastasis. Breast Cancer Res (2011) 13(6):R128. doi: 10.1186/bcr3074

61. Abe P, Mueller W, Schütz D, MacKay F, Thelen M, Zhang P, et al. CXCR7 prevents excessive CXCL12-mediated downregulation of CXCR4 in migrating cortical interneurons. Development (2014) 141(9):1857-63. doi: $10.1242 /$ dev.104224

62. Coggins NL, Trakimas D, Chang SL, Ehrlich A, Ray P, Luker KE, et al. CXCR7 controls competition for recruitment of $\beta$-arrestin 2 in cells expressing both CXCR4 and CXCR7. PloS One (2014) 9(6):e98328. doi: 10.1371/ journal.pone. 0098328

63. Levoye A, Balabanian K, Baleux F, Bachelerie F, Lagane B. CXCR7 heterodimerizes with CXCR4 and regulates CXCL12-mediated G protein signaling. Blood (2009) 113(24):6085-93. doi: 10.1182/blood-2008-12196618

64. Gonzalez H, Hagerling C, Werb Z. Roles of the immune system in cancer: from tumor initiation to metastatic progression. Genes Dev (2018) 32(1920):1267-84. doi: 10.1101/gad.314617.118

65. Meiron M, Zohar Y, Anunu R, Wildbaum G, Karin N. CXCL12 (SDF1alpha) suppresses ongoing experimental autoimmune encephalomyelitis by selecting antigen-specific regulatory T cells. J Exp Med (2008) 205(11):264355. doi: $10.1084 /$ jem. 20080730

66. Karin N. The multiple faces of CXCL12 (SDF-1alpha) in the regulation of immunity during health and disease. J Leukoc Biol (2010) 88(3):463-73. doi: $10.1189 / \mathrm{jlb} .0909602$

67. Ao M, Franco OE, Park D, Raman D, Williams K, Hayward SW. Cross-talk between paracrine-acting cytokine and chemokine pathways promotes malignancy in benign human prostatic epithelium. Cancer Res (2007) 67 (9):4244-53. doi: 10.1158/0008-5472.can-06-3946

68. Jiang K, Li J, Zhang J, Wang L, Zhang Q, Ge J, et al. SDF-1/CXCR4 axis facilitates myeloid-derived suppressor cells accumulation in osteosarcoma microenvironment and blunts the response to anti-PD-1 therapy. Int Immuno Pharmacol (2019) 75:105818. doi: 10.1016/j.intimp.2019.105818

69. Sánchez-Martín L, Sánchez-Mateos P, Cabañas C. CXCR7 impact on CXCL12 biology and disease. Trends Mol Med (2013) 19(1):12-22. doi: 10.1016/j.molmed.2012.10.004

70. Zhao K, Yao Y, Luo X, Lin B, Huang Y, Zhou Y, et al. LYG-202 inhibits activation of endothelial cells and angiogenesis through CXCL12/CXCR7 pathway in breast cancer. Carcinogenesis (2018) 39(4):588-600. doi: $10.1093 /$ carcin/bgy007

71. Infantino S, Moepps B, Thelen M. Expression and regulation of the orphan receptor $\mathrm{RDC1}$ and its putative ligand in human dendritic and B cells. J Immunol (2006) 176(4):2197-207. doi: 10.4049/jimmunol.176.4.2197

72. Wang L, Liu Y, Han R, Beier UH, Thomas RM, Wells AD, et al. Mbd2 promotes foxp3 demethylation and T-regulatory-cell function. Mol Cell Biol (2013) 33(20):4106-15. doi: 10.1128/mcb.00144-13

73. Tarnowski M, Liu R, Wysoczynski M, Ratajczak J, Kucia M, Ratajczak MZ. CXCR7: a new SDF-1-binding receptor in contrast to normal CD34(+) progenitors is functional and is expressed at higher level in human malignant hematopoietic cells. Eur J Haematol (2010) 85(6):472-83. doi: $10.1111 / j .1600-0609.2010 .01531 . x$

74. Wani N, Nasser MW, Ahirwar DK, Zhao H, Miao Z, Shilo K, et al. C-X-C motif chemokine 12/C-X-C chemokine receptor type 7 signaling regulates breast cancer growth and metastasis by modulating the tumor microenvironment. Breast Cancer Res (2014) 16(3):R54. doi: 10.1186/bcr3665

75. Song ZY, Wang F, Cui SX, Gao ZH, Qu XJ. Correction: CXCR7/CXCR4 heterodimer-induced histone demethylation: a new mechanism of colorectal tumorigenesis. Oncogene (2019) 38(28):5747. doi: 10.1038/s41388-019-0836-0

76. Xu J, Liang J, Meng YM, Yan J, Yu XJ, Liu CQ, et al. Vascular CXCR4 Expression Promotes Vessel Sprouting and Sensitivity to Sorafenib Treatment in Hepatocellular Carcinoma. Clin Cancer Res (2017) 23 (15):4482-92. doi: 10.1158/1078-0432.ccr-16-2131

77. Meng YM, Liang J, Wu C, Xu J, Zeng DN, Yu XJ, et al. Monocytes/ Macrophages promote vascular CXCR4 expression via the ERK pathway in hepatocellular carcinoma. Oncoimmunology (2018) 7(3):e1408745. doi: $10.1080 / 2162402 x .2017 .1408745$
78. Singh RK, Lokeshwar BL. The IL-8-regulated chemokine receptor CXCR7 stimulates EGFR signaling to promote prostate cancer growth. Cancer Res (2011) 71(9):3268-77. doi: 10.1158/0008-5472.can-10-2769

79. Watanabe K, Penfold ME, Matsuda A, Ohyanagi N, Kaneko K, Miyabe Y, et al. Pathogenic role of CXCR7 in rheumatoid arthritis. Arthritis Rheum (2010) 62(11):3211-20. doi: 10.1002/art.27650

80. Ngamsri KC, Müller A, Bösmüller H, Gamper-Tsigaras J, Reutershan J, Konrad FM. The Pivotal Role of CXCR7 in Stabilization of the Pulmonary Epithelial Barrier in Acute Pulmonary Inflammation. J Immunol (2017) 198 (6):2403-13. doi: $10.4049 /$ jimmunol.1601682

81. Dai X, Tan Y, Cai S, Xiong X, Wang L, Ye Q, et al. The role of CXCR7 on the adhesion, proliferation and angiogenesis of endothelial progenitor cells. J Cell Mol Med (2011) 15(6):1299-309. doi: 10.1111/j.1582-4934.2011.01301x

82. Maishi N, Ohga N, Hida Y, Akiyama K, Kitayama K, Osawa T, et al. CXCR7: a novel tumor endothelial marker in renal cell carcinoma. Pathol Int (2012) 62(5):309-17. doi: 10.1111/j.1440-1827.2012.02792.x

83. Yamada K, Maishi N, Akiyama K, TowfikAlam M, Ohga N, Kawamoto T, et al. CXCL12-CXCR7 axis is important for tumor endothelial cell angiogenic property. Int J Cancer (2015) 137(12):2825-36. doi: 10.1002/ijc.29655

84. Salazar N, Carlson JC, Huang K, Zheng Y, Oderup C, Gross J, et al. A Chimeric Antibody against ACKR3/CXCR7 in Combination with TMZ Activates Immune Responses and Extends Survival in Mouse GBM Models. Mol Ther (2018) 26(5):1354-65. doi: 10.1016/j.ymthe.2018.02.030

85. Liu H, Xue W, Ge G, Luo X, Li Y, Xiang H, et al. Hypoxic preconditioning advances CXCR4 and CXCR7 expression by activating HIF-1 $\alpha$ in MSCs. Biochem Biophys Res Commun (2010) 401(4):509-15. doi: 10.1016/ j.bbrc.2010.09.076

86. Stacer AC, Fenner J, Cavnar SP, Xiao A, Zhao S, Chang SL, et al. Endothelial CXCR7 regulates breast cancer metastasis. Oncogene (2016) 35(13):1716-24. doi: 10.1038/onc.2015.236

87. Perez-Zsolt D, Martinez-Picado J, Izquierdo-Useros N. When Dendritic Cells Go Viral: The Role of Siglec-1 in Host Defense and Dissemination of Enveloped Viruses. Viruses (2019) 12(1):8. doi: 10.3390/v12010008

88. Ricart BG, John B, Lee D, Hunter CA, Hammer DA. Dendritic cells distinguish individual chemokine signals through CCR7 and CXCR4. J Immunol (2011) 186(1):53-61. doi: 10.4049/jimmunol.1002358

89. Nakano H, Lyons-Cohe MR, Whitehead GS, Nakano K, Cook DN. Distinct functions of CXCR4, CCR2, and CX3CR1 direct dendritic cell precursors from the bone marrow to the lung. J Leukoc Biol (2017) 101(5):1143-53. doi: $10.1189 / \mathrm{jlb} .1 \mathrm{~A} 0616-285 \mathrm{R}$

90. Kabashima K, Shiraishi N, Sugita K, Mori T, Onoue A, Kobayashi M, et al. CXCL12-CXCR4 engagement is required for migration of cutaneous dendritic cells. Am J Pathol (2007) 171(4):1249-57. doi: 10.2353/ ajpath.2007.070225

91. Smith N, Pietrancosta N, Davidson S, Dutrieux J, Chauveau L, Cutolo P, et al. Natural amines inhibit activation of human plasmacytoid dendritic cells through CXCR4 engagement. Nat Commun (2017) 8:14253. doi: 10.1038/ncomms 14253

92. Righi E, Kashiwagi S, Yuan J, Santosuosso M, Leblanc P, Ingraham R, et al. CXCL12/CXCR4 blockade induces multimodal antitumor effects that prolong survival in an immunocompetent mouse model of ovarian cancer. Cancer Res (2011) 71(16):5522-34. doi: 10.1158/0008-5472.can-10-3143

93. Eckert F, Schilbach K, Klumpp L, Bardoscia L, Sezgin EC, Schwab M, et al. Potential Role of CXCR4 Targeting in the Context of Radiotherapy and Immunotherapy of Cancer. Front Immunol (2018) 9:3018:3018. doi: 10.3389/fimmu.2018.03018

94. Gliwiński M, Piotrowska M, Iwaszkiewicz-Grześ D, Urban-Wójciuk Z, Trzonkowski P. Therapy with $\mathrm{CD} 4(+) \mathrm{CD} 25(+) \mathrm{T}$ regulatory cells should we be afraid of cancer? Contemp Oncol (Pozn) (2019) 23(1):1-6. doi: 10.5114/wo.2019.84110

95. Shimizu Y, Dobashi K, Imai H, Sunaga N, Ono A, Sano T, et al. CXCR4 +FOXP3+CD25+ lymphocytes accumulate in CXCL12-expressing malignant pleural mesothelioma. Int J Immunopathol Pharmacol (2009) 22(1):43-51. doi: 10.1177/039463200902200106

96. Santagata S, Napolitano M, D’Alterio C, Desicato S, Di Maro S, Marinelli L, et al. T-regulatory cells efficiently suppress local immunity in renal cancer: targeting CXCR4 reverts the suppressive activity. Oncotarget (2017) 8 (44):77110-20. doi: 10.18632/oncotarget.20363 
97. Polimeno M, Napolitano M, Costantini S, Portella L, Esposito A, Capone F, et al. Regulatory T cells, interleukin (IL)-6, IL-8, vascular endothelial growth factor (VEGF), CXCL10, CXCL11, epidermal growth factor (EGF) and hepatocyte growth factor (HGF) as surrogate markers of host immunity in patients with renal cell carcinoma. BJU Int (2013) 112(5):686-96. doi: 10.1111/bju.12068

98. Fialova A, Partlova S, Sojka L, Hromadkova H, Brtnicky T, Fucikova J, et al. Dynamics of T-cell infiltration during the course of ovarian cancer: the gradual shift from a Th17 effector cell response to a predominant infiltration by regulatory T-cells. Int J Cancer (2013) 132(5):1070-9. doi: 10.1002/ijc.27759

99. Hiraoka N, Onozato K, Kosuge T, Hirohashi S. Prevalence of FOXP3+ regulatory $\mathrm{T}$ cells increases during the progression of pancreatic ductal adenocarcinoma and its premalignant lesions. Clin Cancer Res (2006) 12 (18):5423-34. doi: 10.1158/1078-0432.ccr-06-0369

100. Fu J, Xu D, Liu Z, Shi M, Zhao P, Fu B, et al. Increased regulatory T cells correlate with CD8 T-cell impairment and poor survival in hepatocellular carcinoma patients. Gastroenterology (2007) 132(7):2328-39. doi: 10.1053/ j.gastro.2007.03.102

101. Kocian P, Sedivcova M, Drgac J, Cerna K, Hoch J, Kodet R, et al. Tumorinfiltrating lymphocytes and dendritic cells in human colorectal cancer: their relationship to KRAS mutational status and disease recurrence. Hum Immunol (2011) 72(11):1022-8. doi: 10.1016/j.humimm.2011.07.312

102. Yan M, Jene N, Byrne D, Millar EK, O’Toole SA, McNeil CM, et al. Recruitment of regulatory $\mathrm{T}$ cells is correlated with hypoxia-induced CXCR4 expression, and is associated with poor prognosis in basal-like breast cancers. Breast Cancer Res (2011) 13(2):R47. doi: 10.1186/bcr2869

103. Maimela NR, Liu S, Zhang Y. Fates of CD8+ T cells in Tumor Microenvironment. Comput Struct Biotechnol J (2019) 17:1-13. doi: 10.1016/j.csbj.2018.11.004

104. Goedhart M, Gessel S, van der Voort R, Slot E, Lucas B, Gielen E, et al. CXCR4, but not CXCR3, drives CD8(+) T-cell entry into and migration through the murine bone marrow. Eur J Immunol (2019) 49(4):576-89. doi: $10.1002 /$ eji.201747438

105. Khan AB, Carpenter B, Santos ESP, Pospori C, Khorshed R, Griffin J, et al. Redirection to the bone marrow improves $\mathrm{T}$ cell persistence and antitumor functions. J Clin Invest (2018) 128(5):2010-24. doi: 10.1172/jci97454

106. Seo YD, Jiang X, Sullivan KM, Jalikis FG, Smythe KS, Abbasi A, et al. Mobilization of CD8(+) T Cells via CXCR4 Blockade Facilitates PD-1 Checkpoint Therapy in Human Pancreatic Cancer. Clin Cancer Res (2019) 25(13):3934-45. doi: 10.1158/1078-0432.ccr-19-0081

107. Sharonov GV, Serebrovskaya EO, Yuzhakova D, Britanova OV, Chudakov DM. B cells, plasma cells and antibody repertoires in the tumour microenvironment. Nat Rev Immunol (2020) 20(5):294-307. doi: 10.1038/s41577-019-0257-x

108. McHeik S, Van Eeckhout N, De Poorter C, Galés C, Parmentier M, Springael JY. Coexpression of CCR7 and CXCR4 During B Cell Development Controls CXCR4 Responsiveness and Bone Marrow Homing. Front Immunol (2019) 10:2970. doi: 10.3389/fimmu.2019.02970

109. Becker M, Hobeika E, Jumaa H, Reth M, Maity PC. CXCR4 signaling and function require the expression of the IgD-class B-cell antigen receptor. Proc Natl Acad Sci U S A (2017) 114(20):5231-6. doi: 10.1073/pnas.1621512114

110. Kometani K, Kurosaki T. Differentiation and maintenance of long-lived plasma cells. Curr Opin Immunol (2015) 33:64-9. doi: 10.1016/j.coi.2015.01.017

111. D’Agostino G, Cecchinato V, Uguccioni M. Chemokine Heterocomplexes and Cancer: A Novel Chapter to Be Written in Tumor Immunity. Front Immunol (2018) 9:2185. doi: 10.3389/fimmu.2018.02185

112. Gu Y, Liu Y, Fu L, Zhai L, Zhu J, Han Y, et al. Tumor-educated B cells selectively promote breast cancer lymph node metastasis by HSPA4-targeting IgG. Nat Med (2019) 25(2):312-22. doi: 10.1038/s41591-018-0309-y

113. Wang Y, Li G, Stanco A, Long JE, Crawford D, Potter GB, et al. CXCR4 and CXCR7 have distinct functions in regulating interneuron migration. Neuron (2011) 69(1):61-76. doi: 10.1016/j.neuron.2010.12.005

114. Qin Y, Zhou Z, Zhang F, Wang Y, Shen B, Liu Y, et al. Induction of Regulatory B-Cells by Mesenchymal Stem Cells is Affected by SDF-1 $\alpha$ CXCR7. Cell Physiol Biochem (2015) 37(1):117-30. doi: 10.1159/000430338

115. De Clercq E. The bicyclam AMD3100 story. Nat Rev Drug Discov (2003) 2 (7):581-7. doi: 10.1038/nrd1134

116. Fahham D, Weiss ID, Abraham M, Beider K, Hanna W, Shlomai Z, et al. In vitro and in vivo therapeutic efficacy of CXCR4 antagonist BKT140 against human non-small cell lung cancer. J Thorac Cardiovasc Surg (2012) 144 (5):1167-1175 e1161. doi: 10.1016/j.jtcvs.2012.07.031

117. Bockorny B, Semenisty V, Macarulla T, Borazanci E, Wolpin BM, Stemmer SM, et al. BL-8040, a CXCR4 antagonist, in combination with pembrolizumab and chemotherapy for pancreatic cancer: the COMBAT trial. Nat Med (2020) 26(6):878-85. doi: 10.1038/s41591-020-0880-x

118. Komorowski MP, McGray AR, Kolakowska A, Eng K, Gil M, Opyrchal M, et al. Reprogramming antitumor immunity against chemoresistant ovarian cancer by a CXCR4 antagonist-armed viral oncotherapy. Mol Ther Oncolytics (2016) 3:16034. doi: 10.1038/mto.2016.34

119. Luker GD, Yang J, Richmond A, Scala S, Festuccia C, Schottelius M, et al. At the bench: Pre-clinical evidence for multiple functions of CXCR4 in cancer. J Leukoc Biol (2020) 26:1-20. doi: 10.1002/JLB.2BT1018-715RR

120. Zabel BA, Wang Y, Lewen S, Berahovich RD, Penfold ME, Zhang P, et al. Elucidation of CXCR7-mediated signaling events and inhibition of CXCR4mediated tumor cell transendothelial migration by CXCR7 ligands. J Immunol (2009) 183(5):3204-11. doi: 10.4049/jimmunol.0900269

121. Luo Y, Azad AK, Karanika S, Basourakos SP, Zuo X, Wang J, et al. Enzalutamide and CXCR7 inhibitor combination treatment suppresses cell growth and angiogenic signaling in castration-resistant prostate cancer models. Int J Cancer (2018) 142(10):2163-74. doi: 10.1002/ijc.31237

122. Gustavsson M, Wang L, van Gils N, Stephens BS, Zhang P, Schall TJ, et al. Structural basis of ligand interaction with atypical chemokine receptor 3. Nat Commun (2017) 8:14135. doi: 10.1038/ncomms14135

123. Hartmann TN, Grabovsky V, Pasvolsky R, Shulman Z, Buss EC, Spiegel A, et al. A crosstalk between intracellular CXCR7 and CXCR4 involved in rapid CXCL12-triggered integrin activation but not in chemokine-triggered motility of human T lymphocytes and CD34+ cells. J Leukoc Biol (2008) 84(4):1130-40. doi: 10.1189/jlb.0208088

124. Behnam AB, Lisok A, Chatterjee S, Poirier JT, Pullambhatla M, Luker ,GD, et al. Targeted Imaging of the Atypical Chemokine Receptor 3 (ACKR3/ CXCR7) in Human Cancer Xenografts. J Nucl Med (2016) 57(6):981-8. doi: 10.2967/jnumed.115.167932

125. Ma W, Liu Y, Wang C, Zhang L, Crocker L, Shen J. Atorvastatin inhibits CXCR7 induction to reduce macrophage migration. Biochem Pharmacol (2014) 89(1):99-108. doi: 10.1016/j.bcp.2014.02.014

126. Kalatskaya I, Berchiche YA, Gravel S, Limberg BJ, Rosenbaum JS, Heveker N. AMD3100 is a CXCR7 ligand with allosteric agonist properties. Mol Pharmacol (2009) 75:1240-7. doi: 10.1124/mol.108.053389

127. Adlere I, Caspar B, Arimont M, Dekkers S, Visser K, Stuijt J, et al. Modulators of CXCR4 and CXCR7/ACKR3 Function. Mol Pharmacol (2019) 96(6):737-52. doi: 10.1124/mol.119.117663

128. Chevigné A, Fievez V, Szpakowska M, Fischer A, Counson M, Plesséria JM, et al. Neutralising properties of peptides derived from CXCR4 extracellular loops towards CXCL12 binding and HIV-1 infection. Biochim Biophys Acta (2014) 1843(5):1031-41. doi: 10.1016/j.bbamcr.2014.01.017

129. Franciszkiewicz K, Boissonnas A, Boutet $M$, Combadière $C$, Mami-Chouaib F. Role of chemokines and chemokine receptors in shaping the effector phase of the antitumor immune response. Cancer Res (2012) 72(24):6325-32. doi: 10.1158/0008-5472.CAN-12-2027

130. Lee L, Gupta M, Sahasranaman S. Immune Checkpoint inhibitors: An introduction to the next-generation cancer immunotherapy. $J$ Clin Pharmacol (2016) 56(2):157-69. doi: 10.1002/jcph.591

131. Maleki Vareki S. High and low mutational burden tumors versus immunologically hot and cold tumors and response to immune checkpoint inhibitors. J Immunother Cancer (2018) 6(1):157. doi: 10.1186/s40425-018-0479-7

132. Haanen JBAG. Converting Cold into Hot Tumors by Combining Immunotherapies. Cell (2017) 170(6):1055-6. doi: 10.1016/j.cell.2017.08.031

133. Duan Q, Zhang H, Zheng J, Zhang L. Turning Cold into Hot: Firing up the Tumor Microenvironment. Trends Cancer (2020) 6(7):605-18. doi: 10.1016/ j.trecan.2020.02.022

134. Ciardiello D, Vitiello P, Cardone C, Martini G, Troiani T, Martinelli E, et al. Immunotherapy of colorectal cancer: Challenges for therapeutic efficacy. Cancer Treat Rev (2019) 76:22-32. doi: 10.1016/j.ctrv.2019.04.003

135. Wang R, Feng W, Wang H, Wang L, Yang X, Yang F, et al. Blocking migration of regulatory $\mathrm{T}$ cells to leukemic hematopoietic microenvironment delays disease progression in mouse leukemia model. Cancer Lett (2020) 469:151-61. doi: 10.1016/j.canlet.2019.10.032 
136. Zeng Y, Li B, Liang Y, Reeves PM, Qu X, Ran C, et al. Dual blockade of CXCL12-CXCR4 and PD-1-PD-L1 pathways prolongs survival of ovarian tumor-bearing mice by prevention of immunosuppression in the tumor microenvironment. FASEB J (2019) 33(5):6596-608. doi: 10.1096/ fj.201802067RR

137. Li B, Zeng Y, Reeves PM, Ran C, Liu W, Qu X, et al. AMD3100 Augments the Efficacy of Mesothelin-Targeted, Immune-Activating VIC-008 in Mesothelioma by Modulating Intratumoral Immunosuppression. Cancer Immunol Res (2018) 6(5):539-51. doi: 10.1158/2326-6066.CIR-17-0530

138. Chen IX, Chauhan VP, Posada J, Ng MR, Wu MW, Adstamongkonkul P, et al. Blocking CXCR4 alleviates desmoplasia, increases T-lymphocyte infiltration, and improves immunotherapy in metastatic breast cancer. Proc Natl Acad Sci U S A (2019) 116(10):4558-66. doi: 10.1073/pnas.1815515116

139. D'Alterio C, Buoncervello M, Ieranò C, Napolitano M, Portella L, Rea G, et al. Targeting CXCR4 potentiates anti-PD-1 efficacy modifying the tumor microenvironment and inhibiting neoplastic PD-1. J Exp Clin Cancer Res (2019) 38(1):432. doi: 10.1186/s13046-019-1420-8

140. Li Z, Wang Y, Shen Y, Qian C, Oupicky D, Sun M. Targeting pulmonary tumor microenvironment with CXCR4-inhibiting nanocomplex to enhance anti-PD-L1 immunotherapy. Sci Adv (2020) 6(20):eaaz9240. doi: 10.1126/ sciadv.aaz 9240

141. Hoellenriegel J, Zboralski D, Maasch C, Rosin NY, Wierda WG, Keating MJ, et al. The Spiegelmer NOX-A12, a novel CXCL12 inhibitor, interferes with chronic lymphocytic leukemia cell motility and causes chemosensitization. Blood (2014) 123:1032-9. doi: 10.1182/blood-2013-03-493924

142. Blanchetot C, Verzijl D, Mujić-Delić A, Bosch L, Rem L, Leurs R, et al. Neutralizing nanobodies targeting diverse chemokines effectively inhibit chemokine function. J Biol Chem (2013) 288:25173-82. doi: 10.1074/ jbc.M113.467969

143. Regenass P, Abboud D, Daubeuf F, Lehalle C, Gizzi P, Riché S, et al. Discovery of a locally and orally active CXCL12 neutraligand (LIT-927) with antiinflammatory effect in a murine model of allergic airway hypereosinophilia. $J$ Med Chem (2018) 61:7671-86. doi: 10.1021/acs.jmedchem.8b00657

Conflict of Interest: The authors declare that the research was conducted in the absence of any commercial or financial relationships that could be construed as a potential conflict of interest.

Copyright (c) 2021 Santagata, Ieranò, Trotta, Capiluongo, Auletta, Guardascione and Scala. This is an open-access article distributed under the terms of the Creative Commons Attribution License (CC BY). The use, distribution or reproduction in other forums is permitted, provided the original author(s) and the copyright owner(s) are credited and that the original publication in this journal is cited, in accordance with accepted academic practice. No use, distribution or reproduction is permitted which does not comply with these terms. 